\title{
Meteorological Connectivity from Regions of High Biodiversity within the McMurdo Dry Valleys of Antarctica
}

\author{
M. KATURJi, ${ }^{\mathrm{a}, \mathrm{e}}$ B. Khan, ${ }^{\mathrm{b}}$ M. SPREnGer, ${ }^{\mathrm{c}}$ R. DAtTA,${ }^{\mathrm{a}}$ K. Joy,${ }^{\mathrm{d}}$ P. ZAWAR-ReZA, ${ }^{\mathrm{a}}$ \\ AND I. HAWES ${ }^{\mathrm{d}}$ \\ ${ }^{a}$ Department of Geography, Centre for Atmospheric Research, University of Canterbury, \\ Christchurch, New Zealand \\ ${ }^{\mathrm{b}}$ Institute of Meteorology and Climate Research-Atmospheric Environmental Research (IMK-IFU), \\ Karlsruher Institut für Technologie, Garmisch-Partenkirchen, Germany \\ ${ }^{\mathrm{c}}$ Institute for Atmospheric and Climate Science, ETH Zürich, Zurich, Switzerland \\ ${ }^{\mathrm{d}}$ School of Biological Science, University of Waikato, Hamilton, New Zealand
}

(Manuscript received 10 January 2019, in final form 26 August 2019)

\begin{abstract}
Meteorological connectivity between biological hot spots of the McMurdo Dry Valleys (MDVs) of Antarctica is thought to play a role in species distribution and abundance through the aeolian transport of bioaerosols. Understanding the potential role of such meteorological connectivity requires an understanding of near-surface wind flow within and between valley airsheds. To address this, we applied Lagrangian wind trajectory modeling to mesoscale (spatial resolution of $\sim 1 \mathrm{~km}$ ) weather model output to predict connectivity pathways, focusing on regions of high biodiversity. Our models produce maps of a likelihood metric of wind connectivity that demonstrate the synoptic and mesoscale dependence of connections between local, nearlocal, and nonlocal areas on wind transport, modulated by synoptic weather and topographic forcing. These connectivity areas can have spatial trends modulated by the synoptic weather patterns and locally induced topographically forced winds. This method is transferrable to other regions of Antarctica for broader terrestrial, coastal, and offshore ecological connectivity research. Also, our analysis and methods can inform better placement of aeolian dust and bioaerosol samplers in the McMurdo Dry Valleys, provide preliminary guidelines behind the meteorological controls of sediment transport and smaller particle distribution, and present quantifiable knowledge informing new hypotheses around the potential of wind acting as a physical driver for biological connectivity in the MDVs.
\end{abstract}

\section{Introduction}

The McMurdo Dry Valleys (MDVs) are glaciated valleys with perennial snow- and ice-covered ridgelines and largely ice-free valley floors. The MDVs are located in the McMurdo Sound of the western coastline of the Ross Sea region with the largest snow- and ice-free area in Antarctica. The mean annual air temperature ranges between $-15^{\circ}$ and $-20^{\circ} \mathrm{C}$, with regular austral summer occurrence of daily maxima of a few degrees above freezing at the valley floor. Annual snowfall varies between 3 and $50 \mathrm{~mm}$ water equivalent with higher precipitation rates occurring toward the coastal margins of

e ORCID: 0000-0002-3368-1469.

Corresponding author: Marwan Katurji, marwan.katurji@ canterbury.ac.nz the MDVs (Chinn 1976; Bromley 1985; Clow et al. 1988; Monaghan et al. 2005; Zawar-Reza and Katurji 2014). The climate of the MDVs has been characterized as a "polar desert" with liquid water availability only during summer, primarily from glacial melt. There are no vertebrate species or plants in the MDVs, and the most abundant form of life is microbial activity, which is highly dependent on moisture availability (Cary et al. 2010).

The meteorological behavior of the MDVs plays a major role in driving variability of available liquid water (Fountain et al. 1999; Smith et al. 1999) that helps to control biodiversity (Kennedy 1993; Fountain et al. 1998). During summer, the energy source for raising surface temperatures and promoting meltwater generation can come from a positive net-all-wave radiation balance (largely controlled by cloud cover and surface albedo) and/or from a turbulent heat flux directed from 
warmer air parcels toward the surface. Variability in seasonal insolation or atmospheric sensible heat flux has very large implications on glacial melt rates; meltwater production can increase by several orders of magnitude due to such anomalies (Doran et al. 2008), which if sustained could affect the life-supporting capacity of the MDVs.

Although not well understood, another important climatic driver of biodiversity is the potential role of wind for inter- and intravalley biological connectivity. Taylor et al. (1993) originally defined landscape connectivity in terms of the degree to which movement among resource patches is facilitated or constrained for dominant biota. In this contribution, we specifically focus on the potential movement of propagules among resource patches in the landscape facilitated by wind motion. Through some in situ sediment collection and biological analysis, it is thought that wind dispersal can control the spatial distribution of some soil invertebrate species around the MDVs (Nkem et al. 2006). Wind transport of sediments can have an indirect impact on both biological and hydrological connectivity. For example, connectivity with lake ecosystems is established when aeolian dust is deposited on frozen lake surfaces and subsequently redistributed into the lake and downstream of it when surface melt occurs during the warmer periods (Jepsen et al. 2010). This resultant hydrological connectivity can then have implications on the availability of soluble and hydrologically transportable nutrients for the biogeochemical cycle of the dry valley ecosystem (Deuerling et al. 2014). Aeolian dust deposition on glaciers can reduce albedo and enhance the available net radiation of the surface energy balance needed to drive the ablation rates and snow and ice mass balance (Oliphant et al. 2014; Hoffman et al. 2016). Wind can also control the transport of soluble iron from the MDVs to the Southern Ocean, affecting local and nonlocal biological productivity (Bhattachan et al. 2015). Nearsurface wind patterns are also important for sand dune morphodynamics, affecting available sediment loading and redistribution (Bourke et al. 2009; Speirs et al. 2008).

It has been previously suggested that microbial communities can be established in remote environments through transport by air currents (Pearce et al. 2009), while there are studies that presented biological evidence of the possible role of wind transported bioaerosols on local and nonlocal microbial diversity. For example, Bowman and Deming (2017) showed, based on basic weather station wind speed and direction measurements, that wind can transport bioaerosols between marine and terrestrial environments within the Ross Sea region of
Antarctica. However, an earlier study from biological samples taken from Miers Valley (one of the smaller dry valleys of Antarctica) suggested that the derived taxonomy from the aerosol measurements do not have a marine signature but are more related to localized environments (Bottos et al. 2014).

Stohl and Sodemann (2010) calculated the residence time of near-surface $(100 \mathrm{~m}$ above ground level) air during January and August using the flexible particle dispersion model (FLEXPART) Lagrangian particle dispersion methods. It was found that the air over the Ross Ice Shelf and most of the coastal Ross Sea region locally recirculates (disconnected from regional advection processes) for up to 16 days during summer and around half that time ( 9 days) during winter with similar periods over the Antarctic Plateau. As a result, local wind circulations can have a large impact on bioaerosol transport and redistribution during the peak biologically active summer period. Bioaerosols can have very extended lifetimes and can survive and evolve on atmospheric transport pathways that extend from several days to weeks (Smets et al. 2016; Burrows et al. 2009). Despite the limited evidence from regional and Antarctic continental-scale bioaerosol transport studies, there are still many unknowns on the potential role of local-scale meteorological conditions in controlling biodiversity within the MDVs. Previous research accounts largely for the synoptic-scale meteorological processes simulated by low-resolution global $(50-\mathrm{km}$ grid resolution) or regional climate models $(20-\mathrm{km}$ grid resolution). This approach might be well suited for continental-scale transport and connectivity studies. However, due to the high degree of complex topography of MDVs ecosystem, a suitable scale-resolving methodology should be implemented if one wants to capture the small-scale variability of meteorology impacting local wind circulation processes. It is therefore important to identify the role of near-surface wind flow on inter- and intravalley airshed connectivity within the MDVs of Antarctica. We identify wind connectivity zones across regions of high biodiversity by the application of Lagrangian trajectory modeling of mesoscale wind fields (spatial resolution of $\sim 1 \mathrm{~km}$ ) simulated by a numerical weather model. We also present the results in the context of the sensitivity of wind trajectories within the MDVs to synoptic atmospheric circulation patterns of the larger Ross Sea region (RSR) and local valley thermal circulations. The premise of this study is the lack of quantifiable knowledge informing new hypotheses around the potential of wind acting as a physical driver for biological connectivity in the MDVs. As shown in other studies, wind laden with dust and microorganisms has a strong potential to ecologically 


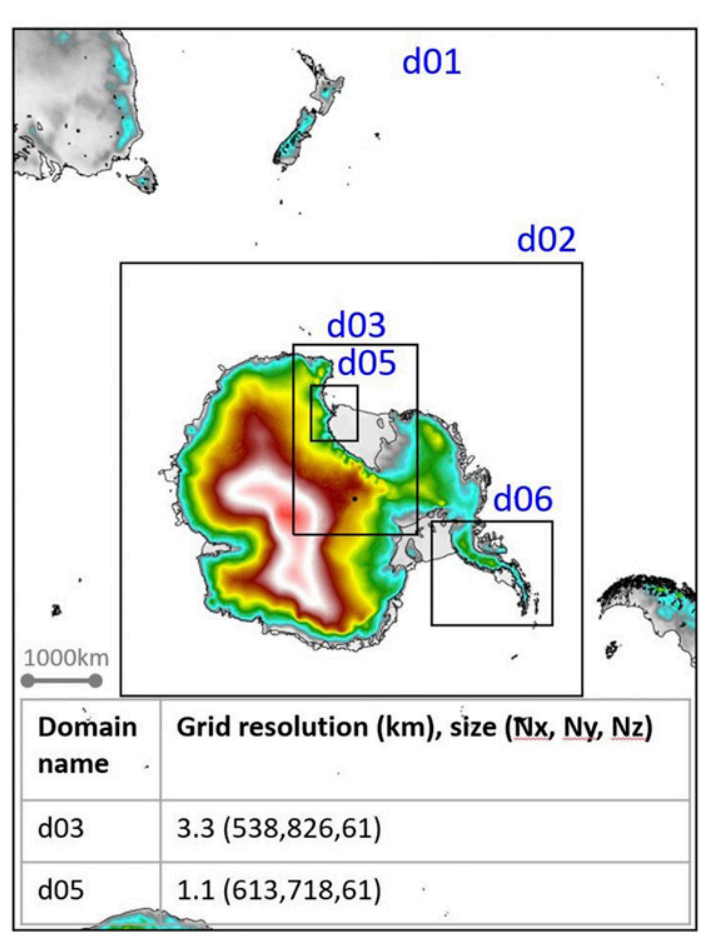

\section{d03, Ross Sea Region}

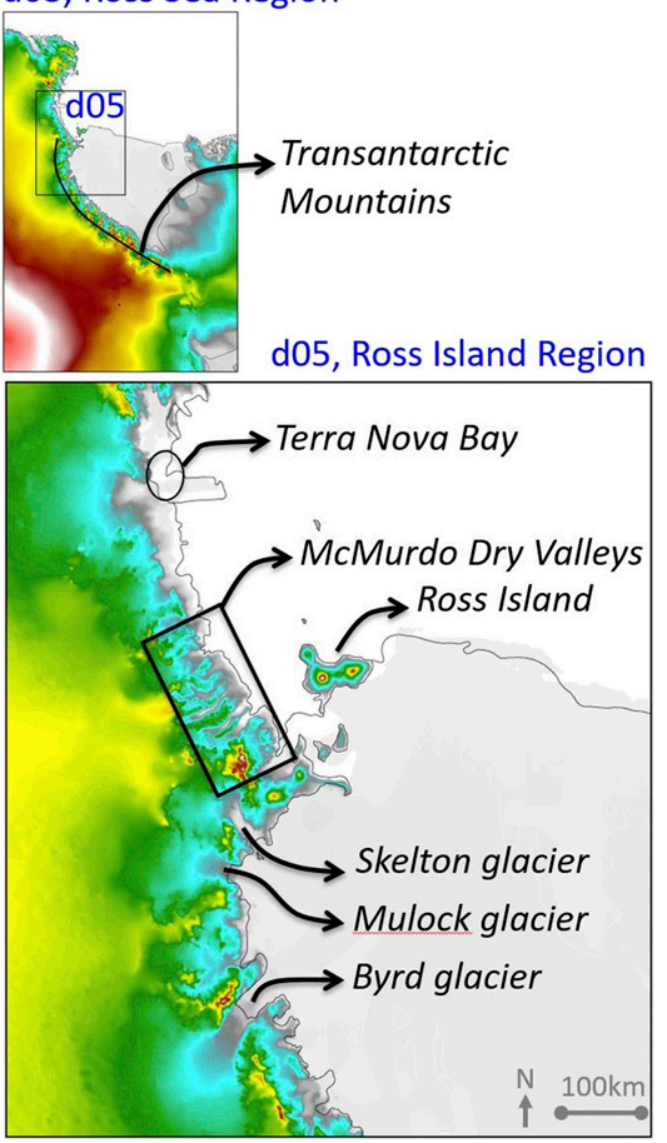

FIG. 1. The AMPS numerical weather modeling domains with referenced geographic landmarks. Domains d03 and d05 were used in this study (the maps are adapted from http://www2.mmm.ucar.edu/rt/amps/).

connect two disparate geographic regions. There is a lack of observational and modeling data for quantification of this connection, all the way from entrainment in the source regions to deposition in the ecological affected geographic location.

The numerical weather modeling data that were used in the analysis along with the automatic weather station datasets will be described in section 2a. The regional atmospheric circulations and the clustering of synoptic weather patterns will be described in section $2 \mathrm{~b}$. The Lagrangian trajectory modeling method along with the experimental design for the wind trajectory construction will be described in section 2c. The results sections will start by a description of regional atmospheric patterns and their impact on the near-surface wind flow fields within the Ross Sea region (section 3a), which will be followed with a description of how local wind fields manifest across the valleys among the different regional atmospheric mean sea level pressure clusters (section 3b). Section $3 c$ will focus on the results of the Lagrangian trajectory modeling with wind connectivity maps, which is finally followed by discussions and conclusions (section 4).

\section{Data and methods}

\section{a. Meteorological data}

The meteorological data used for this study are primarily from a numerical weather prediction (NWP) model. Wind vectors for the trajectory analysis are extracted from the Antarctic Mesoscale Prediction System (AMPS; Powers et al. 2012) output. AMPS is a real-time NWP model currently supporting weather forecasting for the U.S. Antarctic Program (USAP) and offers NWP data for scientific and logistical support. AMPS is a modified version of the Weather Research and Forecasting (WRF) Model (Skamarock et al. 2008) running on computational grids ranging from the continental scale to Ross Island scale (Fig. 1). Some of the meteorological data used for this study came from the grid domain that covers the Ross Sea (d03 at 3.3-km grid spacing, and 3-h temporal resolution), and some from 

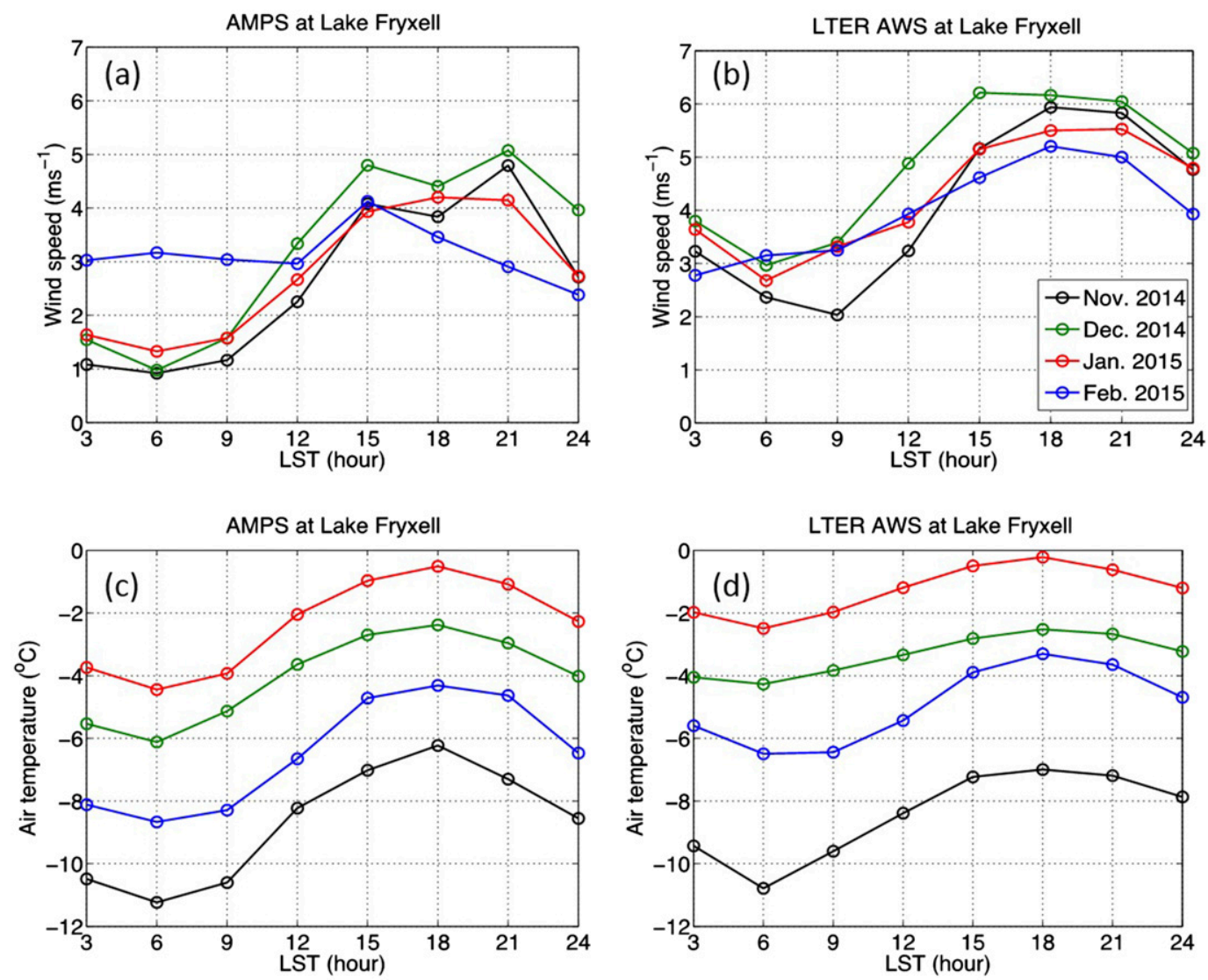

FIG. 2. Three-hourly mean composite of near-surface (a),(b) wind speed and (c),(d) air temperature from Lake Fryxell for (left) AMPS domain 03 and (right) observations from the LTER AWS. The Lake Fryxell AWS is located at a latitude of -77.611491 and longitude of 163.176357 , with an elevation of $19 \mathrm{~m}$ ASL; wind speed and air temperature were measured at $3 \mathrm{~m}$ AGL. The 3-hourly means were derived from the 15-min-averaged data on the logger that was logging every $4 \mathrm{~s}$ for wind speed and $30 \mathrm{~s}$ for air temperature. All LTER AWS data can be retrieved online (http://mcm.lternet.edu/meteorology-data-sets).

the grid domain that covers McMurdo Dry Valley (d05 at $1.1-\mathrm{km}$ grid spacing, and $1-\mathrm{h}$ temporal resolution). AMPS includes improved physical parameterizations to better model the environmental conditions of the polar regions (such as treatments of the sea ice and glacier surfaces). AMPS has been verified extensively for the Ross Ice Shelf region, Ross Island, and West Antarctica (Bromwich et al. 2013; Powers 2007; Nigro et al. 2011, 2012; Wille et al. 2016; Deb et al. 2016; Tastula et al. 2012) and was found to predict wind speed and direction to a reasonable accuracy, with a general overestimation of wind speed by $2 \mathrm{~ms}^{-1}$. This bias was attributed to the underestimation of atmospheric boundary layer stability in the model's schemes. For the dry valleys, Speirs et al. (2010) showed that AMPS predicts the onset of synoptic strong wind changes reasonably well. A specific validation was carried out for AMPS for this study covering the study period and shown in Fig. 2. Different line colors in Fig. 2 show data from four different months starting in November 2014 and ending in February 2015. The 3-hourly composite metric shows very good agreement between AMPS at 3-km spatial resolution with observations. The diurnal oscillation cycle in wind speed and air temperature is very well predicted by AMPS within this complex terrain. Overall AMPS exhibited a slight underestimation of wind speeds and a cold bias of around $2^{\circ} \mathrm{C}$ during the late-night and early-morning periods. The real-time weather forecast data from AMPS are available online (http://www2.mmm.ucar.edu/rt/amps/), and archived data can be retrieved from the Climate Data Gateway (AMPS archive 2018). All long-term ecological research (LTER) automatic weather station (AWS) station data can be retrieved online (http:// mcm.lternet.edu/meteorology-data-sets).

\section{b. Synoptic weather typing}

The period considered for this study covers the 2014/15 austral summer. To attribute selected meteorological 


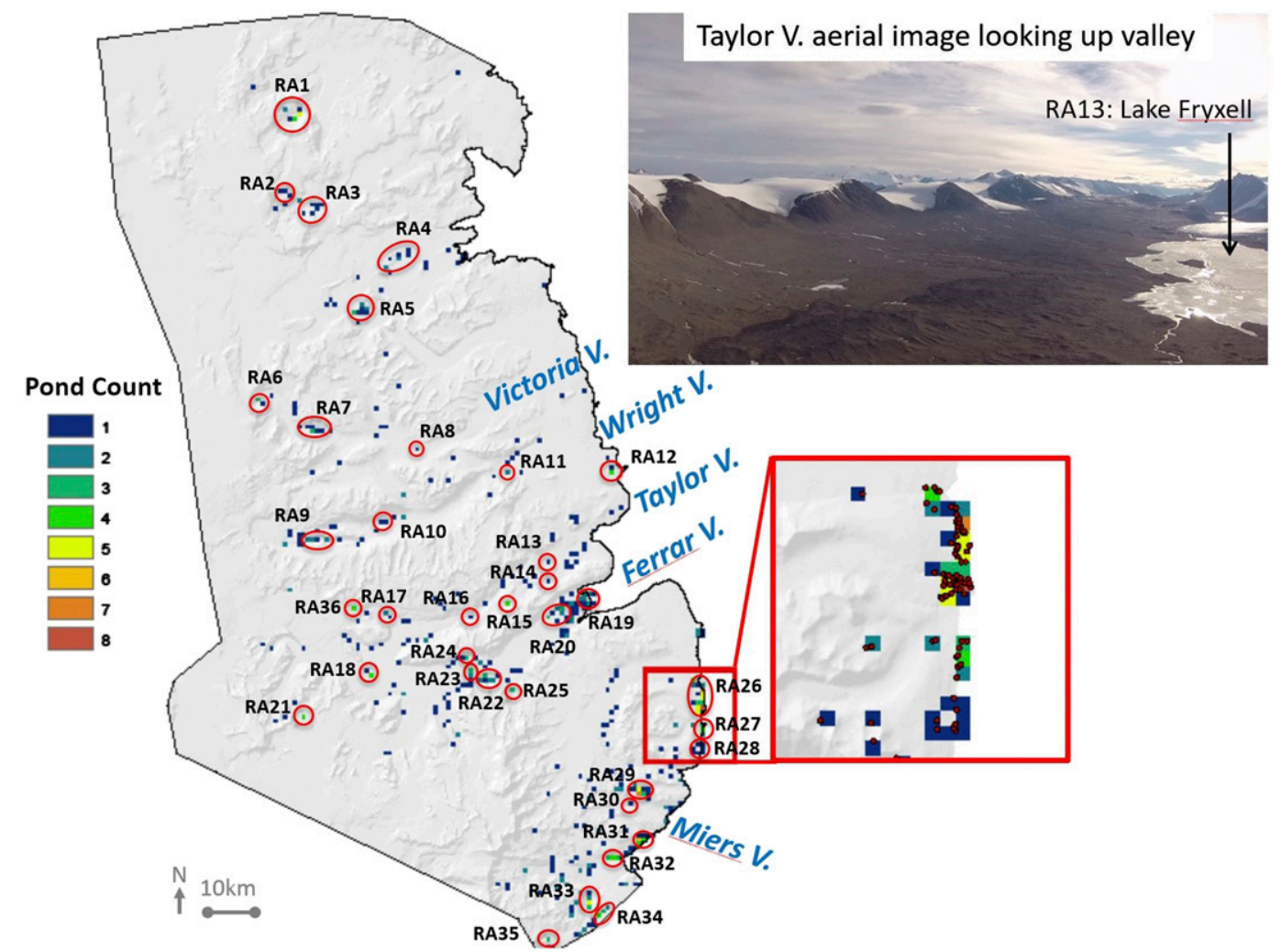

FIG. 3. The McMurdo Dry Valleys (outlined by a thick black rectangle in domain d05 of Fig. 1) topography, showing locations and density per of ponds/lakes per kilometer squared. The red square inset shows both the actual pond/lake count and the cumulative rasterized data as per the color scale used. Locations of chosen initial backward and forward trajectory release areas (RA) are outlined by a red circle. The 36 release areas were chosen to represent at least a $3 \mathrm{~km}$ by $3 \mathrm{~km}$ area, with at least three ponds in this area with the exception of the existence of larger lake features (see Table 1 for a full list of release areas).

periods used for the mesoscale (from AMPS domain d05 at spatial resolution of $1.1 \mathrm{~km}$ ) Lagrangian trajectory modeling (section $2 \mathrm{c}$ ) to the wider synoptic circulation patterns (from AMPS domain d03 at spatial resolution of $3.3 \mathrm{~km}$ ) we have first carried out synoptic circulation pattern clustering. The synoptic weather typing was used to identify prevailing yet distinct summertime circulation patterns as explained later in this section. This approach mainly allows for a reduction in the total number of meteorological periods used for the Lagrangian trajectory modeling, but it justifies the selection of representative meteorological events that were resolved by a nested higher-resolution numerical weather-modeling grid while attributed to specific larger circulation patterns. The total number of synoptic weather types (or nodes as explained below) was nine, and there were eight selected meteorological periods spreading across the nine different synoptic classifications (see section 3), each representing a continuous weather event that spanned a minimum period of $24 \mathrm{~h}$ or more occurring under the representative synoptic forcing. A minimum of 24-h period criteria was used to ensure that the diurnal forcing was included in these events. A maximum time cutoff allowed for extending a meteorological period was based on the condition that the event moved from its current synoptic weather type to another cluster.

The Ross Sea regional circulation pattern clustering was performed on the mean sea level pressure (MSLP) output of the AMPS domain d03 using an artificial neural network training and pattern recognition algorithm based on a self-organizing map (SOM) scheme. Application of the SOM technique to meteorological data (such as MSLP) has been previously proven to be very successful and has also been applied to gridded meteorological data (e.g., Sheridan and Lee 2011; Nigro et al. 2011; Richardson et al. 2003). Our group has also applied the SOM method to two-dimensional vertical profiles of temperature within the boundary layer (Katurji et al. 2015) and three-dimensional datasets of surface brightness temperature measured by infrared cameras over a natural landscape (Katurji and Zawar-Reza 2016). 
A total of four months (1 November 2014 to 1 March 2015) of 3-hourly time steps of derived MSLP data were used in the SOM construction. As a result, there were 960 sets of two-dimensional matrices that equate to around 240800 variables used for the SOM training stages. The algorithm used was SOM_PAK (http://www.cis.hut.fi/ research/som-research/nnrc-programs.shtml). MSLP spatial anomalies were first calculated based on the spatial deviation of each pixel from the mean of the entire pixels within the domain of interest at each time step. Then the spatial anomalies were normalized by the temporal standard deviation of each pixel. This allowed for scaling the MSLP data to a range between -3 and +3 for effective pattern extraction without being biased toward large anomalies within the dataset usually caused by topography. The second stage includes a map initialization step, by which the map is initialized using random numbers for a rectangular topology and an optimized selected map size of 3 by 3 nodes. The third stage is the map training, which is carried out by an initial ordering of the surfaces or maps, then with a longer iteration for tuning the maps for the final emergence of a selforganized pattern for each selected node reflecting the similarity to the entire node's input data. A rectangular topology with a learning rate parameter of 0.02 and a radius of 3 , which is normally no longer than the maximum SOM node size, was used to setup the SOM. The final stage was quantifying the quality of learning. A quantization error and the Sammon map (Sammon 1969) were used as criterion for successful SOM output. The Sammon map generates a 2D plot of the nodes connected by lines with distances representing the Euclidean distances among the input vectors or data.

\section{c. Lagrangian trajectory modeling}

To investigate the strength of wind connectivity between biological hot spots in the McMurdo Dry Valleys trajectories were generated over the selected meteorological events in both forward and backward trajectory modes. The Lagrangian trajectory model used for this study is Lagranto, which was initially developed to use the output from the European Centre for Medium-Range Weather Forecasts (ECMWF; Wernli and Davies 1997), but is now also coupled with other models, including AMPS/WRF (Sprenger and Wernli 2015). Lagranto uses the three-dimensional kinematic wind fields $(u, v$, and $w$ components of wind velocity) of AMPS/WRF on model levels to calculate three-dimensional trajectories; that is, the trajectories rely on the model-resolved gridscale flow. It does not introduce any additional stochastic turbulence signal to account for the lack of the representation of turbulent processes at the grid-scale
TABLE 1. The number of lakes/ponds from each of the release areas showing elevation above sea level and geographic location.

\begin{tabular}{|c|c|c|c|}
\hline $\begin{array}{c}\text { Release } \\
\text { area }\end{array}$ & $\begin{array}{c}\text { No. of } \\
\text { ponds/lakes }\end{array}$ & $\begin{array}{c}\text { Release area } \\
\text { mean elev } \\
(\mathrm{m})\end{array}$ & Lat, lon $\left(^{\circ}\right)$ \\
\hline RA1 & 13 & 700 & $-76.719,161.004$ \\
\hline RA2 & 3 & 1580 & $-76.868,160.861$ \\
\hline RA3 & 6 & 1100 & $-76.915,161.079$ \\
\hline RA4 & 8 & 500 & $-77.005,161.822$ \\
\hline RA5 & 12 & 970 & $-77.113,161.551$ \\
\hline RA6 & 4 & 860 & $-77.297,160.666$ \\
\hline RA7 & 7 & 480 & $-77.350,161.165$ \\
\hline RA8 & 1 (Lake Vida) & 330 & $-77.388,161.938$ \\
\hline RA9 & 7 & 540 & $-77.557,161.011$ \\
\hline RA10 & 1 (Lake Vanda) & 50 & $-77.529,161.578$ \\
\hline RA11 & 1 (Lake Brownworth) & 250 & $-77.436,162.741$ \\
\hline RA12 & 5 & 100 & $-77.443,163.705$ \\
\hline RA13 & 1 (Lake Fryxell) & 4 & $-77.613,163.174$ \\
\hline RA14 & 1 (Spaulding Pond) & 250 & $-77.659,163.117$ \\
\hline RA15 & 4 & 750 & $-77.699,162.712$ \\
\hline RA16 & 1 (Lake Bonney) & 100 & $-77.697,162.516$ \\
\hline RA17 & 3 & 350 & $-77.718,161.609$ \\
\hline RA18 & 5 & 800 & $-77.838,161.427$ \\
\hline RA19 & 16 & 3 & $-77.693,163.500$ \\
\hline RA20 & 15 & 30 & $-77.733,163.186$ \\
\hline RA21 & 4 & 1600 & $-77.913,160.825$ \\
\hline RA22 & 13 & 500 & $-77.839,162.526$ \\
\hline RA23 & 9 & 610 & $-77.842,162.383$ \\
\hline RA24 & 6 & 650 & $-77.812,162.365$ \\
\hline RA25 & 4 & 750 & $-77.873,162.749$ \\
\hline RA26 & 40 & 3 & $-77.892,164.545$ \\
\hline RA27 & 12 & 6 & $-77.963,164.523$ \\
\hline RA28 & 7 & 10 & $-78.013,164.502$ \\
\hline RA29 & 19 & 780 & $-78.068,163.851$ \\
\hline RA30 & 1 (Lake Miers) & 30 & $-78.098,163.851$ \\
\hline RA31 & 21 & 50 & $-78.175,163.967$ \\
\hline RA32 & 14 & 100 & $-78.201,163.726$ \\
\hline RA33 & 12 & 350 & $-78.290,163.450$ \\
\hline RA34 & 10 & 550 & $-78.309,163.616$ \\
\hline RA35 & 3 & 1000 & $-78.366,163.072$ \\
\hline RA36 & 3 & 830 & $-78.697,161.282$ \\
\hline
\end{tabular}

level. The turbulent processes (higher-order nonlinear terms in the momentum equation) are parameterized by the AMPS/WRF mesoscale model (Skamarock et al. 2008), which are then added to the mean flow to form the 3D wind flow input to Lagranto. In Antarctica, Lagranto was recently used to study foehn jets over the Larsen C Ice Shelf in Antarctica (Elvidge et al. 2015; Elvidge and Renfrew 2016).

Back trajectories were released from 36 locations including ponds and lakes within the McMurdo Dry Valleys as shown in Fig. 3 and detailed in Table 1. A total number of 201 passive tracers were released from along the two diagonals of a $1 \mathrm{~km}^{2}$ box around each of the release areas shown in Fig. 3. The backward trajectory modeling was then carried out for each of the 201 tracers for different meteorological periods described 
Node 1: $149,15.5$

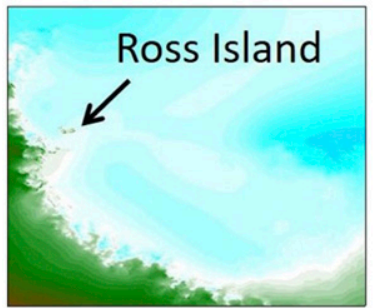

Node 4: 96,10.0

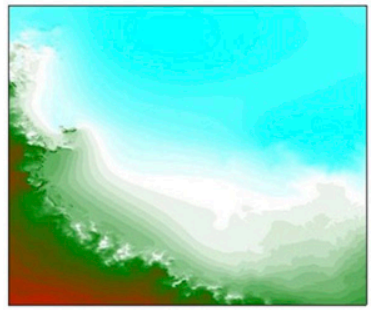

Node 7: 131,13.6

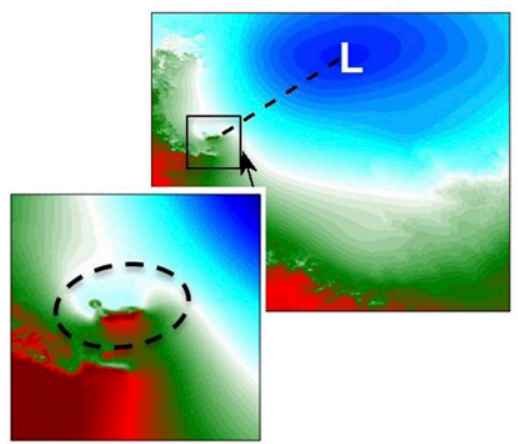

Node 2: $81,8.4$

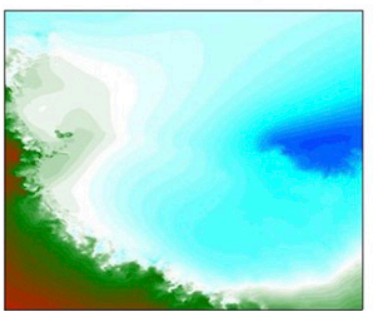

Node 5: 107,11.1

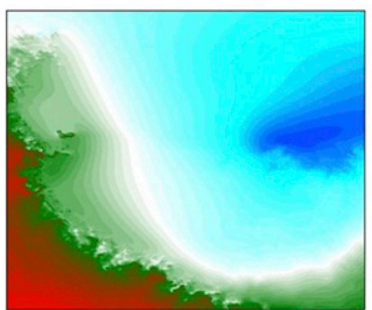

Node 8: 100,10.4

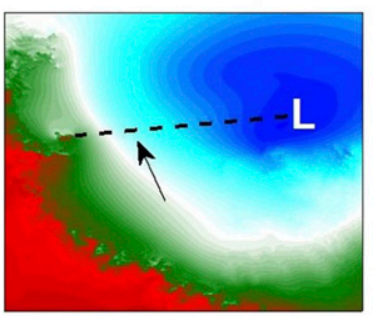

Node 3: 115,12.0

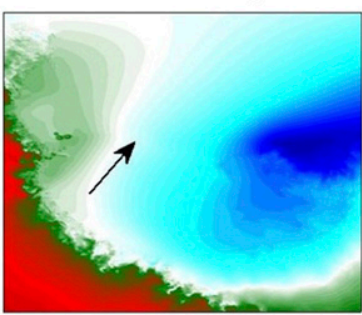

Node 6: 70,7.3

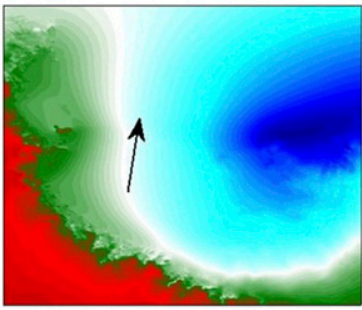

Node 9: 111,11.6

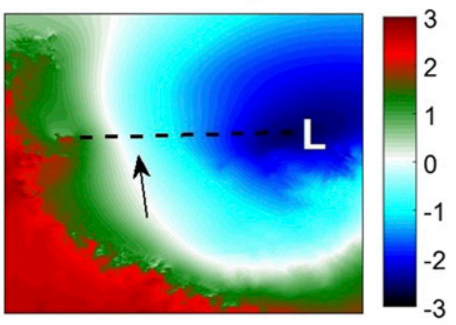

FIG. 4. Self-organizing map showing a 3 by 3 matrix of SOM derived pressure distribution across d03 (3-km resolution; see Fig. 1) of AMPS. Red or blue colors respectively show positive or negative normalized mean sea level pressure spatial anomalies (see section $2 \mathrm{~b}$ for how the normalization was carried out), and arrows represent the expected near-surface wind direction based on the regional pressure gradients. Numbers (e.g., "149, 15.5" for node 1) on top of each subplot of the matrix represent the count and percent occurrence of that specific pressure map. A total of 960 pressure distribution time steps (at 3-hourly intervals) were used in the clustering over the 1 Nov 2014-1 Mar 2015 analysis period. The dashed circle in node 7 shows the leeside negative pressure anomaly of Ross Island.

in section $3 \mathrm{c}$ using three-dimensional kinematic tracing at a temporal resolution of $5 \mathrm{~min}$.

To summarize the large number of trajectories, we have chosen to construct kernel density estimates (KDE) based on a Gaussian probability function fitted to the trajectory points in the two-dimensional space (Bowman and Azzalini 1997). The result of the KDE was a contour of the 75th percentile of the highest likelihood of occurrence of trajectory densities.

\section{Results and discussion}

\section{a. Ross Sea region self-organizing map}

A 3 by 3 matrix or 9 nodes (Fig. 4) represent the SOM from AMPS domain d03 (MDV) MSLP data. Each of the nodes show a composite average of the MSLP spatial anomaly of all data occurrences within the specific node. The SOM algorithm sequences the maps with increasing pressure gradients toward the bottom right and decreasing pressure gradients toward the top left of the SOM matrix (Fig. 4). For example, node 1 represents the most frequently occurring pressure distribution (15.5\% of the time of relatively settled weather due to the weak pressure gradients) as opposed to the least frequently occurring node $6(7.3 \%$ of the time of relatively unsettled weather across the Ross Sea region due to the strong pressure gradients).

Node 9, along with nodes 7 and 8 , represents the lowest negative pressure perturbation in the Ross Sea region (see Fig. 4), which produces unsettled weather and 

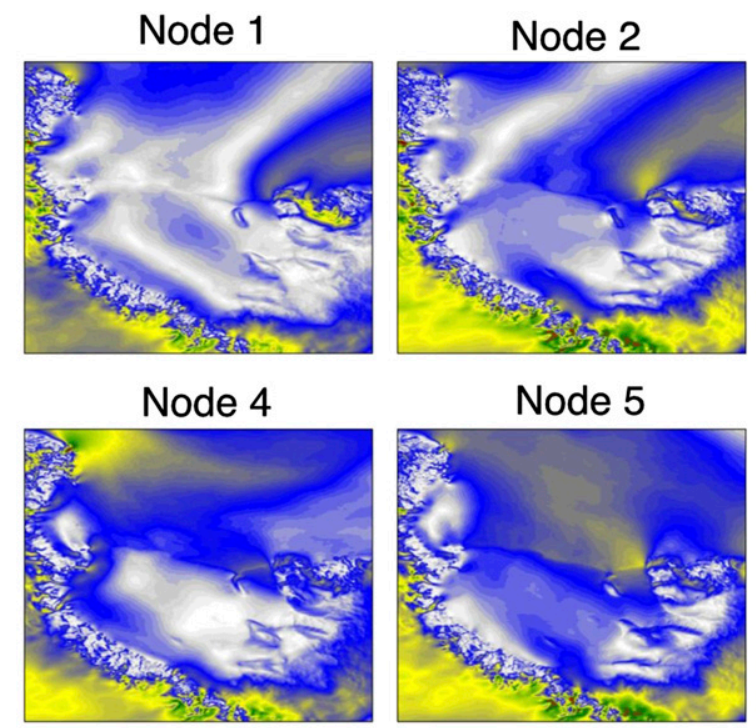

Node 7

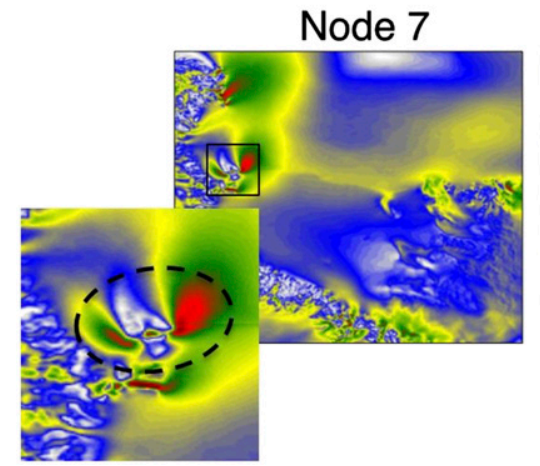

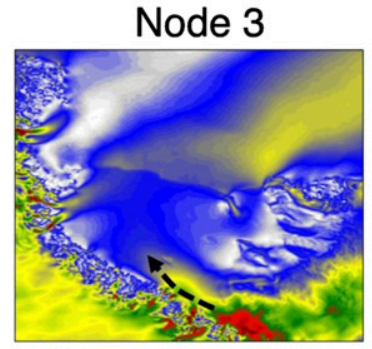
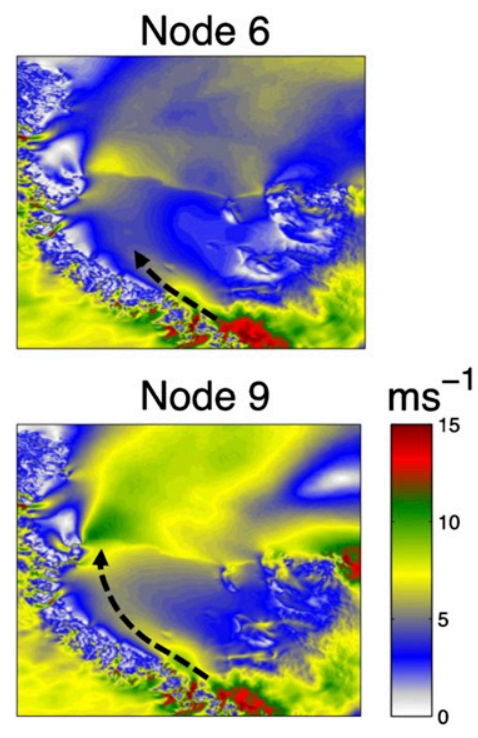

FIG. 5. Derived composite mean surface wind speed from AMPS d03 (3-km resolution) corresponding to each of the pressure distribution clustered maps (see Fig. 4) from the SOM output. The dashed circle in node 7 shows tip jets to the right and left of Ross Island.

predominantly southerly flow regimes around the Ross Island region (Seefeldt and Cassano 2012). The low atmospheric pressure anomaly located in the northeast sector of the Ross Sea region is a climatological low pressure system in this region and is sometimes referred to as the Ross-Amundsen Sea low (Raphael et al. 2016).

The pressure gradients from the SOM-derived MSLP distributions in Fig. 4 cause variations in near-surface wind speed patterns and intensity across the Ross Sea region. The composite mean per node of the $10 \mathrm{~m}$ AGL wind speed of domain d03 is shown in Fig. 5. Node 1 (Fig. 5) shows widespread low wind speeds due to small pressure gradients of node 1 (Fig. 4). In contrast, node 7 shows higher wind speeds maintained by a well-developed low pressure system to the northeast of Ross Island. Nodes 7, 8, and 9 result in strong prevailing wind flows from the southeast direction tending to more southerly directions for node 9. As a result, the near-surface wind direction in node 7 is close to orthogonal to the major axis of Ross Island (see black arrow in node 7 Fig. 4), which produces a noticeable lee side pressure depression (within the black dotted circle of node 7 of Fig. 4). This particular flow regime produces a mesoscale flow known as a tip jet on both sides of Ross Island that is evident in node 7 of Fig. 5 (dotted circle). This mesoscale adjustment results from the shift of the pressure gradient from being orthogonal to the flow (in the upwind region of topography) to parallel to the flow when the flow is no longer blocked by topography (Outten et al. 2009).

Node 3 (Fig. 4) shows high pressure perturbations on the western coast of the Ross Sea region with the center of the low pressure to the furthest eastern location of the Ross Sea region. As a result, node 3 pressure patterns allow for the development of offshore high wind speeds (Fig. 5) flowing out from major glaciated valleys like the Skelton, Mulock, and Byrd glaciers (see Fig. 1 for geographic reference). This particular surface wind flow 
pattern in response to the regional atmospheric pressure gradients has been identified before in Nigro and Cassano (2014). As the eastern low pressure system strengthens, the offshore flow reduces and a new mesoscale wind flow pattern emerges along the Transantarctic Mountain coastline (see dotted arrow of node 9 in Fig. 5). This phenomenon is known as the barrier jet flow and is a geostrophic flow adjustment due to topographically induced pressure gradients resulting from cold air mass convergence on the windward side of topography, in this case the Transantarctic Mountain topography. The barrier jet flow was previously studied and identified in this area (Seefeldt et al. 2007; Nigro and Cassano 2014).

\section{b. Dry valley surface wind patterns}

To demonstrate the inter- and intravalley surface wind flow patterns simulated by the higher-resolution domain $\mathrm{d} 05$ of AMPS, the mean composite time-averaged wind vector of the MDVs area at $1.1-\mathrm{km}$ resolution is shown in Fig. 6. Examples from nodes 1, 3, and 7 were chosen because they represent a weak synoptic pressure gradient case (node 1), a west-to-east positive pressure gradient allowing for the development of offshore flows (node 3 ), and a strong synoptic southerly wind flow over the Ross Island region (node 7).

For node 1 in Fig. 6a, all of the marked major valleys, Wright, Taylor, and Ferrar glacier valleys, and the smaller Miers Valley show a relatively weak up-valley flow near the coastal end of the valleys. Aside from Miers Valley, there are flow convergence zones between the down-valley and up-valley flow regimes. These convergence zones, within the red circles of Fig. 6a, produce low wind speeds and a circulation or shift in wind direction. The summertime surface wind patterns and valley thermal circulations from automatic weather station data have been previously studied by Doran et al. (2002) and Monaghan et al. (2005). They also show distinctive upper- and lower-valley climatic zones controlled by the diurnal valley thermal circulations; these diurnal oscillations persist throughout the summer period but vary in intensity depending on the intraseasonal variability in insolation.

Node 3 (Fig. 6b) corresponds to a regional zonal positive pressure gradient (see node 3 of Fig. 6). Mean wind vectors show lower and less persistent up-valley winds for the coastal ends of the dry valley area. However, there appears to be an influence from the west-to-east pressure gradient that is reflected by higher down-valley wind speeds for Taylor and Ferrar glacier valley when compared with node 1 , particularly noticeable in the upper-valley sections (see the red dotted box of Fig. 6b). Node 7 (Fig. 6c) corresponds to the case of strong
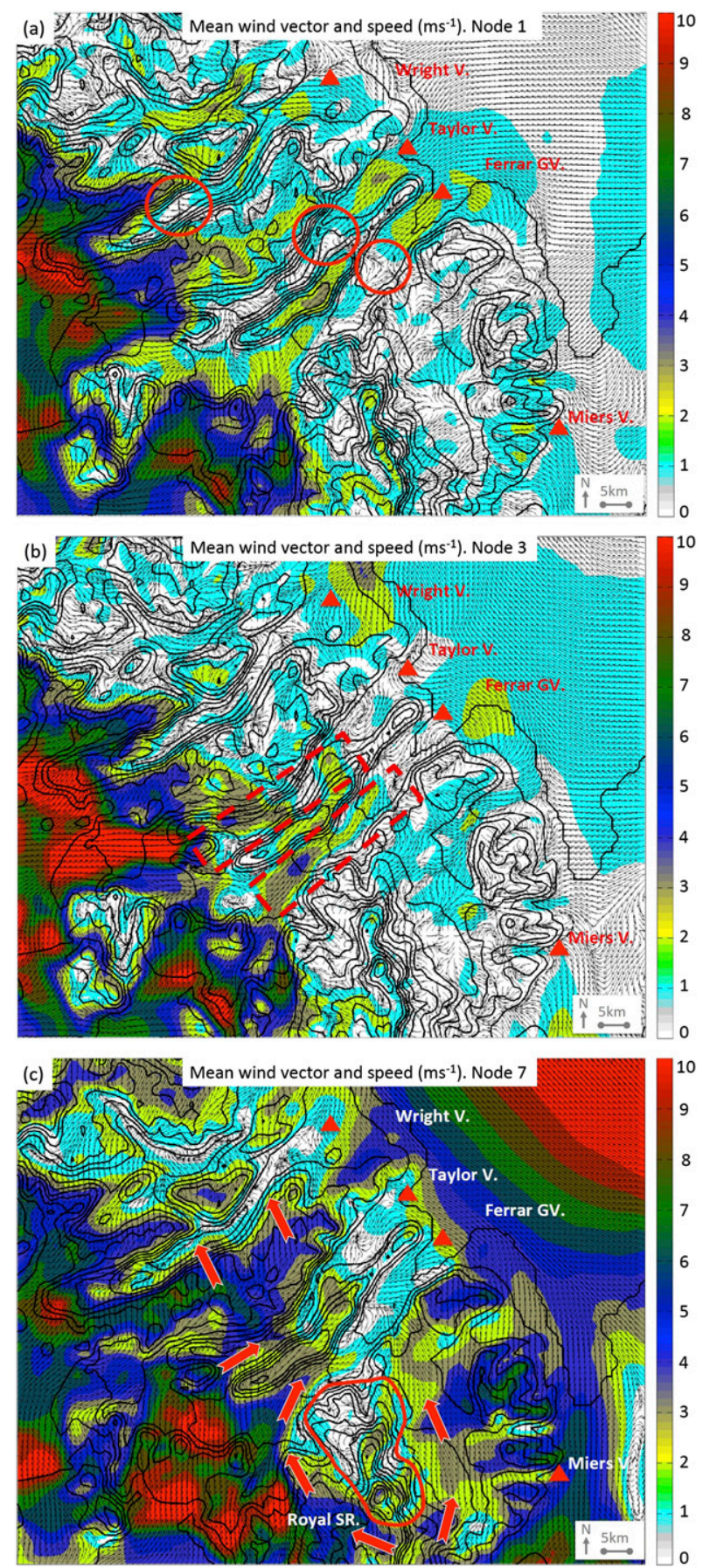

FIG. 6. Composite mean surface wind vector (black arrows) and speed ( $\mathrm{m} \mathrm{s}^{-1}$; contour colors) from AMPS d05 (1-km resolution) for nodes (a) 1, (b) 3, and (c) 7. The red circles in (a) show the areas of wind convergence due to the up- and down-valley wind direction diurnal changes within the synoptic circulation type represented in node 1 . The red rectangles in (b) highlight the valley-floor region of Taylor and the Ferrar glacier valleys, and the thick red arrows in (c) summarize the overall flow direction of node 7 surrounding the high-elevation Royal Society Ranges, also circled by a red line. 
(a)

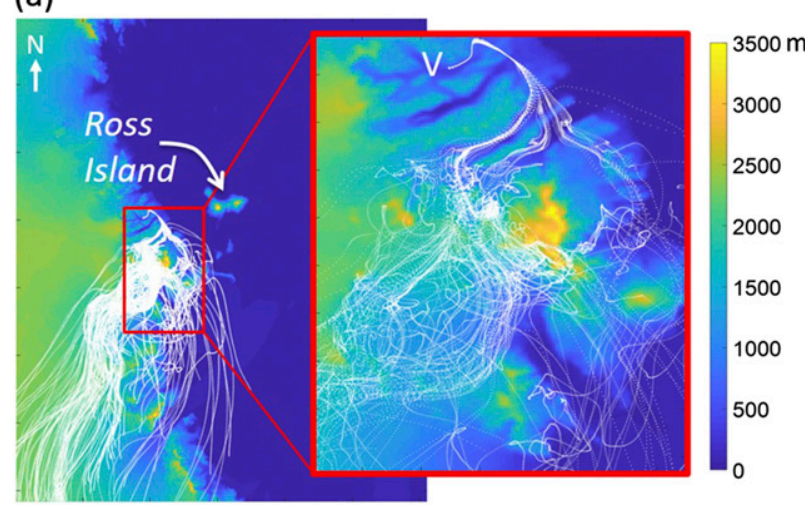

(b)

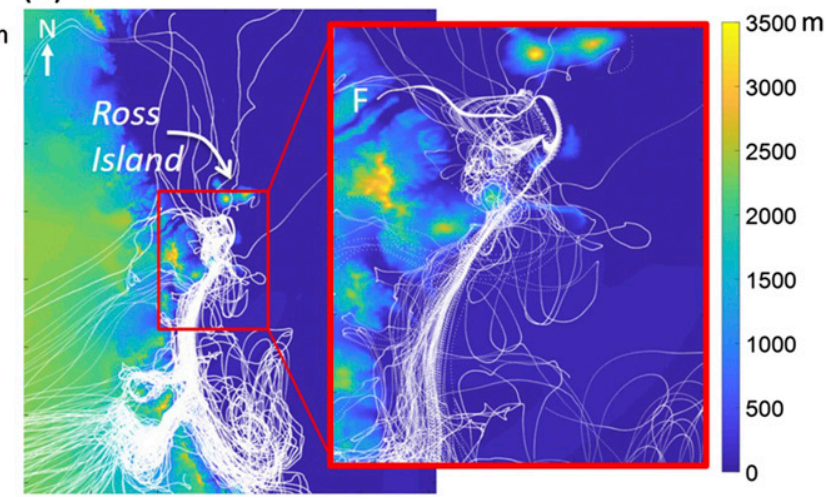

FIG. 7. Example of back trajectories from tracking 200 release points starting at $2 \mathrm{~m}$ above ground level for (a) Lake Vida (the point labeled "V") for a period of 2 days and (b) Lake Fryxell (the point labeled "F") for a period of 7 days. The figure insets zoom in on the highlighted local region of the MDV.

synoptic southerly wind regimes (see node 7 in Fig. 4), and as a result the offshore wind speeds are higher than in nodes 1 and 3 (Fig. 6). The higher wind speeds at the top-right corner of Fig. $6 \mathrm{c}$ (in the ranges of $7 \mathrm{~m} \mathrm{~s}^{-1}$ and higher) concentrate to the left side of Ross Island's tip jet also shown in the regional domain of node 7 of Fig. 5. Despite the prevailing southerly wind regime, there is still an inter- and intravalley variability of near-surface wind velocity reflected in the wind vector composite mean of node 7. The north and south ridgelines of Miers Valley are lower in elevation than the ridgelines of the larger upper valleys like Wright and Taylor, so as a result, Miers Valley does not exhibit a strong topographic influence on the wind direction and the AMPS model shows cross-valley flows (from south to north) for Miers Valley. The Royal Society Ranges (red circle in Fig. 6c) appear to block and divert the southerly flow (as illustrated by the red arrows of Fig. 6c), which then is topographically steered as down-valley flow in the Ferrar glacier and Taylor Valley.

\section{c. Wind trajectories and connectivity}

This section presents the results of the three-dimensional kinematic backward Lagrangian trajectories and the derived KDE to describe the likelihood of meteorological connectivity across the MDVs. Given the fourmonth period of study and the fact that synoptic weather patterns have typical time scales of less than a week, we aimed to sample a variety of synoptic types. This criterion was used to select the periods within which the wind trajectories were constructed from, as a result, there were eight chosen meteorological periods to calculate the trajectories from and they were chosen to include a minimum of a 24-h period or longer. (The meteorological periods from which the trajectory calculations were based are listed in the caption of Fig. 9, described in more detail below.) These periods belong to the nine different synoptic classes or SOM nodes shown in Fig. 4 (with starting and ending times listed in the caption of Fig. 9). Figure 7 shows an example of 201 back trajectories released from two different areas for a specific meteorological period that spans 7 days and illustrates modeled paths of air parcels that would have reached Lake Vida (Fig. 7a) and Lake Fryxell (Fig. 7b). This specific example shows a southerly wind flow field that is steered and deflected by the high topography and sometimes is heavily influenced by Ross Island as in the example in Fig. $7 b$.

The complete set of trajectory lines include repeating the example presented in Fig. 7 for the 36 release areas covering 8 different meteorological periods. We have chosen to simplify the presented trajectory information by constructing the KDE revealing the highest likelihood of trajectory clusters or densities. The KDE contours show regions of high likelihood of trajectory density that emerge either from the convergence of the flow field or the localized circulations of the flow field within topographic constraints. Figure 8 illustrates four different examples of the KDE 50th top percentile contours of the 200 trajectory lines from four different release areas. These examples differ by the release area and/or meteorological period but reveal a range of local (within the MDV; Fig. 8a) and nonlocal likelihood (outside the MDV; Fig. 8b) of atmospheric transport to the designated ponds/lake areas. Figures $8 \mathrm{c}$ and $8 \mathrm{~d}$ also show the impact of topography like Ross Island and Taylor Valley in strongly modifying the flow field and resulting in sharp gradients in the KDE contour lines.

Figure 9 is a summary of all back trajectories constructed from a large subset of the 36 release areas under the eight different meteorological periods belonging to different synoptic classes shown as figure insets in Fig. 9. 
RA1 Traj. (white dots) and 50th perc. KDE (contour)

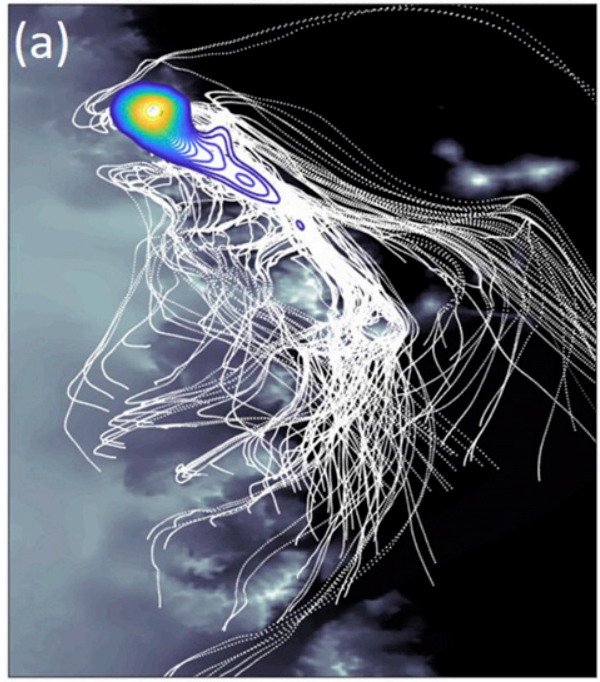

RA16 Traj. (white dots) and 50th perc. KDE (contour)

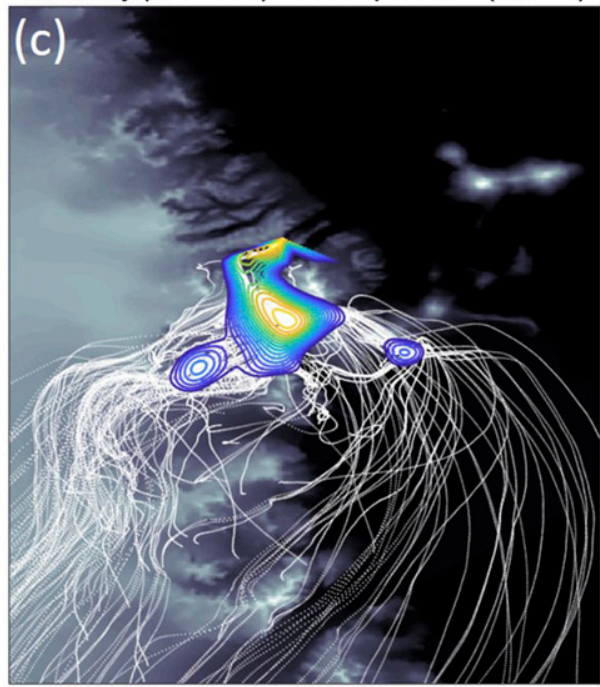

RA9 Traj. (white dots) and 50th perc. KDE (contour)

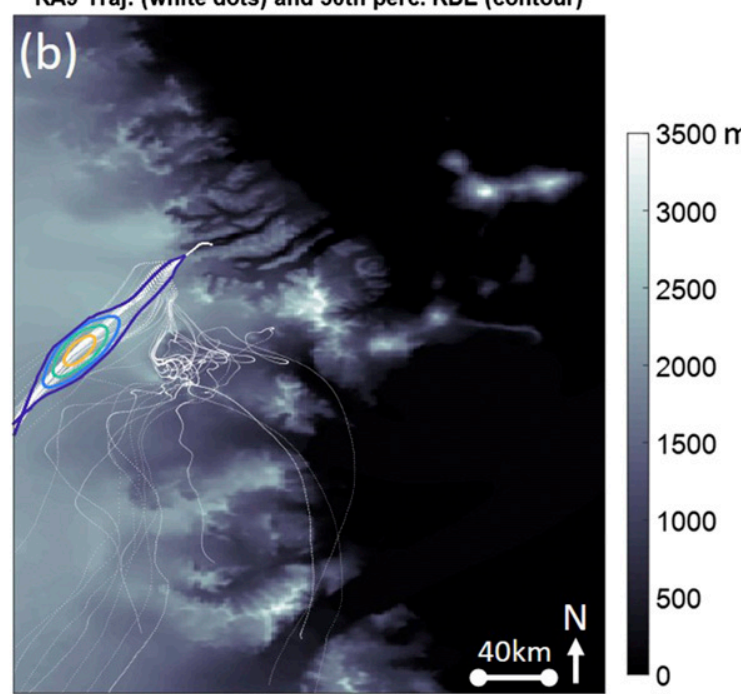

RA13 Traj. (white dots) and 50th perc. KDE (contour)

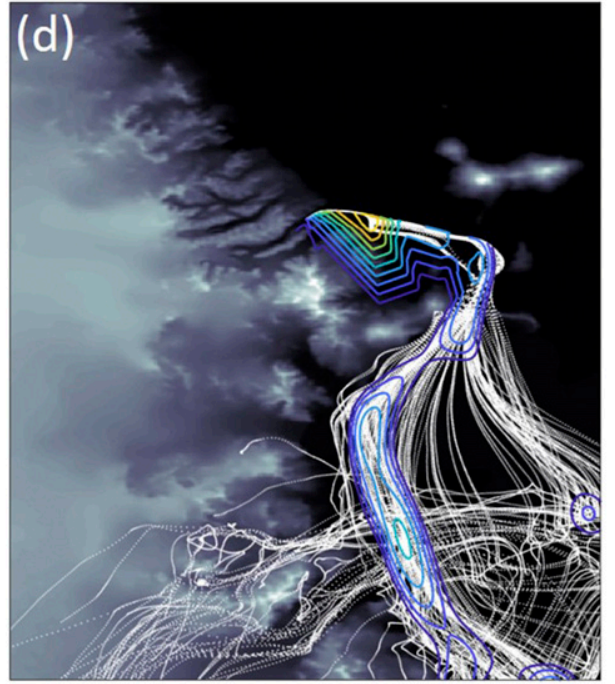

FIG. 8. Four examples of KDE contour lines for 50th percentile and above for 200 back trajectories from release areas (a) RA1 (northern MDV), (b) RA9 (western Wright Valley), (c) RA16 (Lake Bonney, Taylor Valley), and (d) RA13 (Lake Fryxell, Taylor Valley). The contour lines are colored on the basis of the KDE probability.

The synoptic classes, as mentioned earlier in Fig. 4, cover a range of strong synoptic pressure gradients like in nodes 7 to 9 and weaker synoptic pressure gradients like in nodes 1 to 5 . The likelihood areas of atmospheric transport into the MDVs are represented by the 75th top percentile contour line and is colored based on the release area identification. There is a wide range of variability across all of the meteorological periods largely controlled by the regional pressure gradient and the expected near-surface wind direction (cf. the upwind contours with the black arrow on the synoptic class insert of Fig. 9). The atmospheric pathway likelihood maps also show a wide range of overlapping contour lines from different release areas indicating a connectivity of spatial footprints of atmospheric transport likelihoods across the release areas. Predictably, under all conditions, flux tends to be more likely south to north than vice versa, and transport within valleys has a high overall probability. The weaker synoptic pressure gradient cases (like in Figs. 8e,f,h) tend to offer local (within the MDV), and near-local (outside the MDV) areas of high likelihood of atmospheric transport into the ponds and lakes, and relatively little opportunity for transport between valleys-although valleys may have common potential sources. The stronger synoptic pressure gradient cases (like in Figs. 9a-c and 8d) tend to offer 
75th perc. PDF contour, period 01, selected RAs

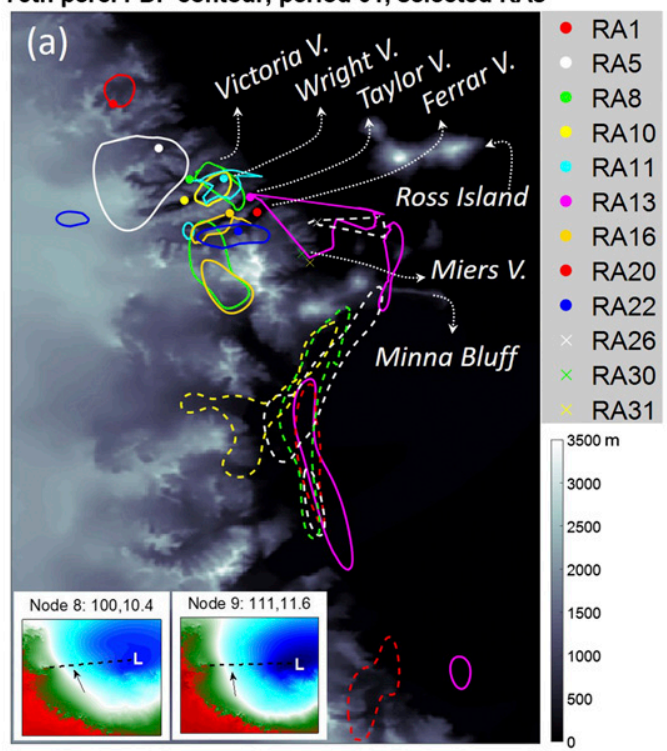

75th perc. PDF contour, period 09, selected RAs

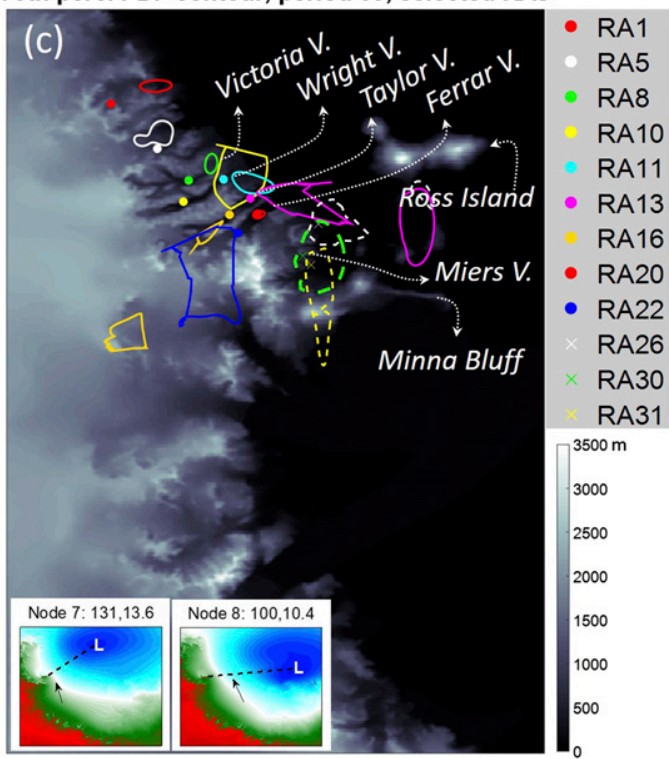

75th perc. PDF contour, period 02, selected RAs

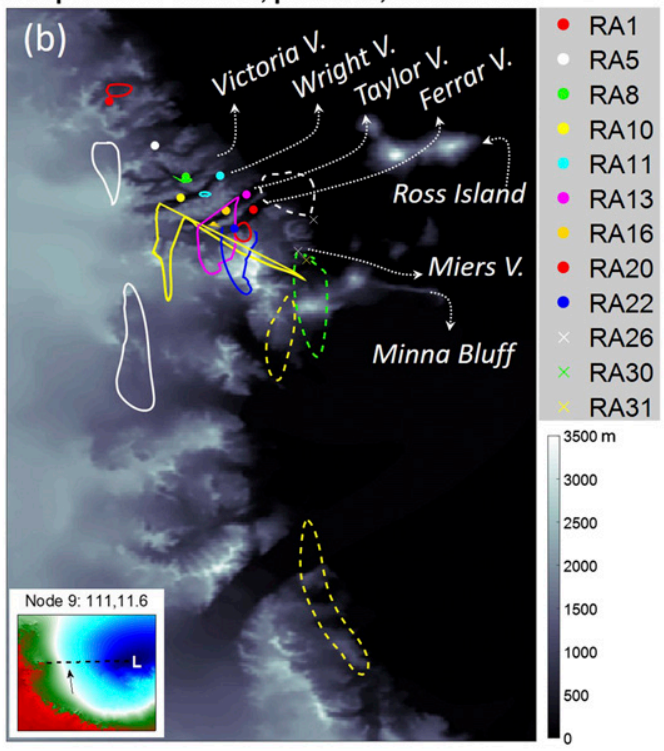

75th perc. PDF contour, period 05 , selected RAs

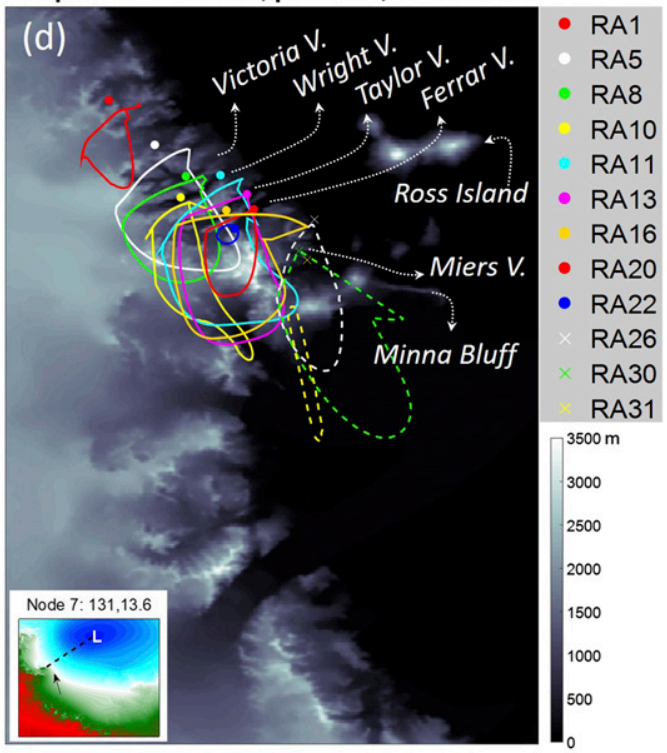

FIG. 9. The 75th-percentile contour lines derived from the KDE of the 200 trajectory lines produced from a subset of the 36 release areas (see Fig. 3) for the eight different meteorological periods that were used for the Lagrangian trajectory modeling that are also distributed across the nine different synoptic weather classes (see lower-left panel inset from Fig. 4). The dates of each meteorological period are (a) 22-24 Nov 2014, (b) 5-7 Dec 2014, (c) 3-5 Jan 2015, (d) 3-7 Feb 2015, (e) 11-17 Jan 2015, (f) 2-3 Feb 2015, (g) 4-10 Nov 2014, and (h) 13-18 Dec 2014.

nonlocal areas of high likelihood of atmospheric transport into the ponds and lakes of the dry valleys, particularly the southern dry valleys (like in Miers), new and nonlocal atmospheric transport pathways could come from areas farther south of Minna Bluff. Node 7 (Fig. 9d), in particular, offers significant potential for south-to-north transport between valleys in the southern and central part of the MDV. Since this node prevails $13.6 \%$ of the time, we can hypothesize that if injection of bioaerosols into aeolian distribution pathways is common, then this mechanism could provide a mechanism for blending of microbial populations within that part of the MDV. The most insular area of the MDV for aeolian connectivity would appear to be the northern region. The mean height above sea level of all trajectories produced for Fig. 9 is $1285 \mathrm{~m}$ with a maximum of $3666 \mathrm{~m}$, whereas the maximum terrain height above sea level is $3714 \mathrm{~m}$. These results also indicate that the air parcels reaching 
75th perc. PDF contour, period 06 , selected RAs

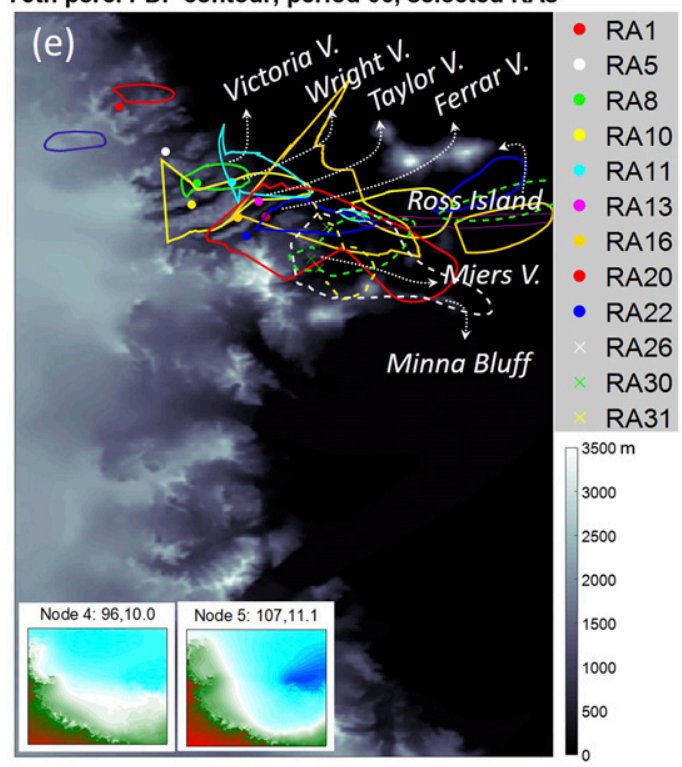

75th perc. PDF contour, period 07 , selected RAs

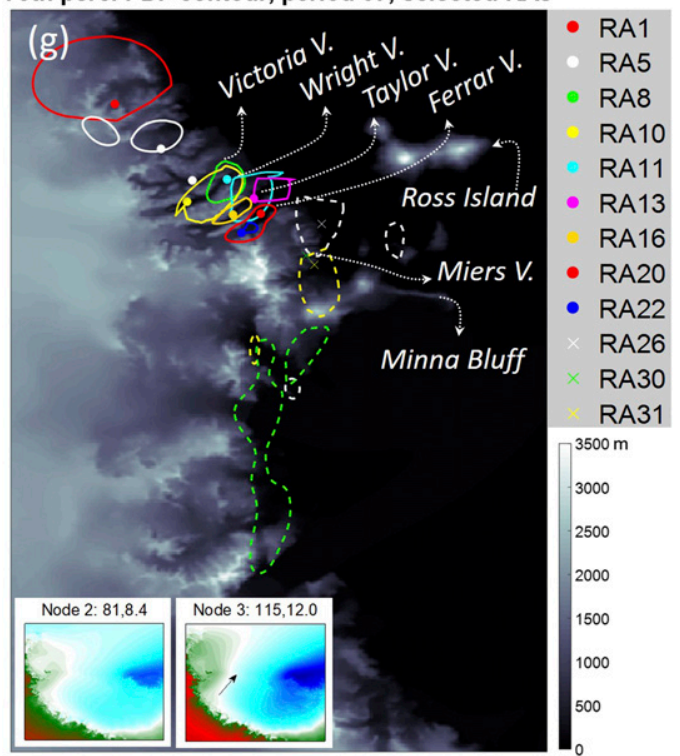

75th perc. PDF contour, period 11 , selected RAs

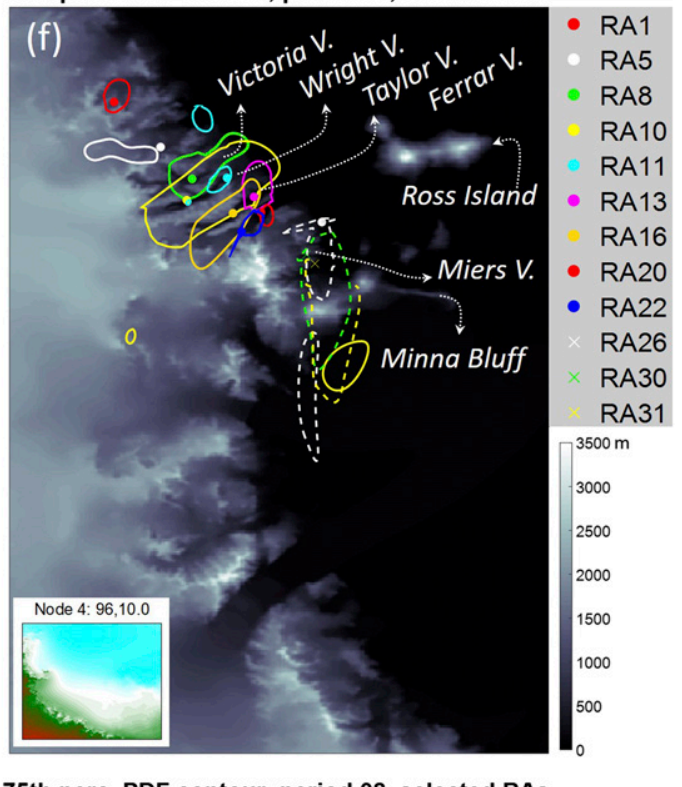

75th perc. PDF contour, period 08 , selected RAs

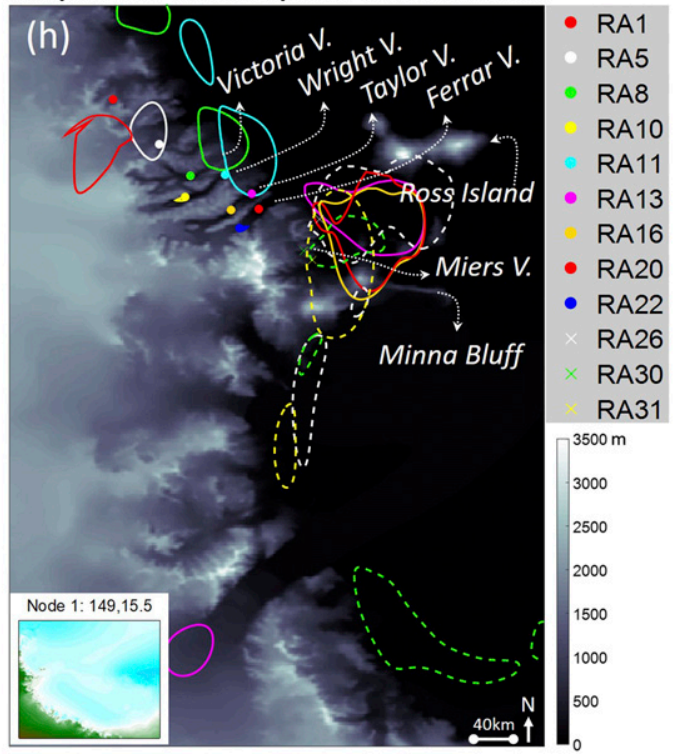

FIG. 9. (Continued)

the biological hot spots over the selected meteorological periods would have remained very closely confined to topography in this region.

Backward trajectories were calculated using the threedimensional velocity field resolved by AMPS/WRF, as a result the air parcels vertical track will reflect atmospheric processes and the interaction with the complex topography. The variability in trajectory height above ground level will depend on the meteorological period and the release area (RA). We have calculated the mean air parcel height profile (results not shown here) of all 201 trajectories for each RA and all of the meteorological periods. The results show that the majority of the mean air parcel AGL heights for all the considered release areas across all meteorological periods tend to be restricted to less than $1000 \mathrm{~m}$ AGL and less than $500 \mathrm{~m}$ closer to the release areas. The complex topography of the dry valleys plays a major role in controlling the height of air parcels as they were traced back through synoptically classified meteorological periods. These results suggest that the majority of the meteorological connectivity across the biological RAs 
presented in this study can occur across pathways that connect the surface to around $1000 \mathrm{~m}$ AGL.

\section{Conclusions}

To understand ecological connectivity across biological hot spots of the McMurdo Dry Valleys of Antarctica, a better understanding of the physical drivers-such as aeolian transport processes - controlling this connectivity is needed. This research has developed quantitative knowledge on the role of wind in connecting areas of high biodiversity within the MDVs. The methods we used developed spatial footprints of atmospheric transport pathways within which wind could play a role in connectivity. Our results show the following:

1) Wind can potentially play a role in bioconnectivity; this was demonstrated by developing maps of a likelihood metric of wind connectivity.

2) There is a synoptic and mesoscale meteorological dependence of local (within one valley), near-local (across valleys), and nonlocal (between valleys and coastal regions) areas controlled by wind transport.

3) The meteorologically connected areas vary depending on the initial release area within MDV location but can have spatial trends modulated by the synoptic weather patterns and locally induced topographic forcing.

4) The mean air parcel trajectory height above ground level for all the considered release areas across all meteorological periods tend to be restricted to less than $1000 \mathrm{~m}$ AGL and less than $500 \mathrm{~m}$ closer to the release areas.

It is vital to understand the potential of atmospheric transport at a meteorological modeling scale that resolves atmospheric boundary layer instabilities, local thermal circulations, and topographically induced wind patterns. Our results demonstrated the applicability of these methods at the regional and local scale of the MDVs, and our methods could be directly transferrable to other regions of Antarctica for broader terrestrial, coastal and offshore ecological connectivity research. The McMurdo Dry Valleys represent a biogeographic region that hosts unique environments within which terrestrial biology thrived due to its isolation and dependence on microscale processes largely decoupled from regionwide variability (Convey et al. 2008; Convey 2010). Our results can help to better inform microbial connectivity studies across the dry valley coastal region (e.g., Bowman and Deming 2017; Bottos et al. 2014) where sometimes conclusions around microbial community similarities across regions can differ, and consequently knowledge about spatial meteorological connectivity, like that presented in this study, could help to support these conclusions. Our analysis and methods can be used to inform better placement of aeolian dust and bioaerosol samplers in the McMurdo Dry Valleys and to design biodiversity surveys to test the importance of insularity within specific valleys. It can also provide preliminary guidelines behind the meteorological controls of sediment transport and smaller particle distribution. A longer-term study of wind connectivity following this presented method for this region or others will be needed to characterize a more representative climatology. The challenge of longterm wind trajectory modeling suitable for resolving mesoscale and microscale processes will be the computational cost of high-resolution meteorological modeling necessary for resolving complex terrain meteorological processes. We think combining weather typing/classification, as presented here, at the regional or synoptic scale with type-based mesoscale high-resolution modeling can make these studies possible. Our analysis and methodology does not include particle dispersion modeling like the approach used in Lagrangian particle dispersion models (LPDM; Stohl et al. 1998; Lin et al. 2003). We derived spatial connectivity maps across various weather types using three-dimensional kinematic Lagrangian back trajectories. We acknowledge that LPDM tools can provide more accurate transport pathways especially when considering subgrid turbulence fields and their impact on dispersion characteristics. However, to comprehensively approach the problem of quantifying meteorological connectivity and particle dispersion pathways, a proper emission inventory and more automatic weather stations are needed. We hope this research and its result could aid in understanding the potential and spatial extent of possible meteorological connectivity as an important initial knowledge base for the Antarctic biological community.

Acknowledgments. The authors thank the anonymous reviewers for their efforts and constructive feedback in the review process of this article. This research was supported by the Ministry of Business and Innovation, New Zealand, under research Contract UOWX1401 for the Dry Valley Ecosystem Resilience Program.

\section{REFERENCES}

Bhattachan, A., L. Wang, M. F. Miller, K. J. Licht, and P. D'Odorico, 2015: Antarctica's Dry Valleys: A potential source of soluble iron to the Southern Ocean? Geophys. Res. Lett., 42, 1912-1918, https://doi.org/10.1002/2015GL063419.

Bottos, E. M., A. C. Woo, P. Zawar-Reza, S. B. Pointing, and S. C. Cary, 2014: Airborne bacterial populations above desert soils of the McMurdo Dry Valleys, Antarctica. Microb. Ecol., 67, 120-128, https://doi.org/10.1007/s00248-013-0296-y. 
Bourke, M. C., R. C. Ewing, D. Finnegan, and H. A. McGowan, 2009: Sand dune movement in the Victoria Valley, Antarctica. Geomorphology, 109, 148-160, https://doi.org/10.1016/ j.geomorph.2009.02.028.

Bowman, A. W., and A. Azzalini, 1997: Applied Smoothing Techniques for Data Analysis. Oxford University Press, 204 pp.

Bowman, J. S., and J. W. Deming, 2017: Wind-driven distribution of bacteria in coastal Antarctica: Evidence from the Ross Sea region. Polar Biol., 40, 25-35, https://doi.org/ 10.1007/s00300-016-1921-2.

Bromley, A. M., 1985: Weather observations, Wright Valley, Antarctica. New Zealand Meteorological Service Internal Publ. 11, 37 pp.

Bromwich, D. H., F. O. Otieno, K. M. Hines, K. W. Manning, and E. Shilo, 2013: Comprehensive evaluation of Polar Weather Research and Forecasting model performance in the Antarctic. J. Geophys. Res. Atmos., 118, 274-292, https://doi.org/10.1029/ 2012JD018139.

Burrows, S., T. Butler, P. Jöckel, H. Tost, A. Kerkweg, U. Pöschl, and M. G. Lawrence, 2009: Bacteria in the global atmosphere: Part 2. Modeling of emissions and transport between different ecosystems. Atmos. Chem. Phys., 9, 9281-9297, https://doi.org/ 10.5194/acp-9-9281-2009.

Cary, S. C., I. R. McDonald, J. E. Barrett, and D. A. Cowan, 2010: On the rocks: The microbiology of Antarctic Dry Valley soils. Nat. Rev. Microbiol., 8, 129-138, https://doi.org/10.1038/ nrmicro2281.

Chinn, T. J., 1976: Hydrological research report, Dry Valleys, Antarctica, 1974-75. New Zealand Ministry of Works and Development, $54 \mathrm{pp}$.

Clow, G. D., C. P. McKay, G. M. Simmons Jr., and R. A. Wharton Jr., 1988: Climatological observations and predicted sublimation rates at Lake Hoare, Antarctica. J. Climate, 1, 715-728, https://doi.org/10.1175/1520-0442(1988) 001<0715:COAPSR $>2.0 . \mathrm{CO} ; 2$.

Convey, P., 2010: Terrestrial biodiversity in Antarctica-Recent advances and future challenges. Polar Sci., 4, 135-147, https:// doi.org/10.1016/j.polar.2010.03.003.

— J. A. E. Gibson, C. D. Hillenbrand, D. A. Hodgson, P. J. A. Pugh, J. L. Smellie, and M. I. Stevens, 2008: Antarctic terrestrial life-Challenging the history of the frozen continent? Biol. Rev. Cambridge Philos. Soc., 83, 103-117, https://doi.org/ 10.1111/j.1469-185X.2008.00034.x.

Deb, P., A. Orr, J. S. Hosking, T. Phillips, J. Turner, D. Bannister, J. O. Pope, and S. Colwell, 2016: An assessment of the Polar Weather Research and Forecasting (WRF) model representation of near-surface meteorological variables over West Antarctica. J. Geophys. Res. Atmos., 121, 1532-1548, https:// doi.org/10.1002/2015JD024037.

Deuerling, K. M., W. B. Lyons, S. A. Welch, and K. A. Welch, 2014: The characterization and role of aeolian deposition on water quality, McMurdo Dry Valleys, Antarctica. Aeolian Res., 13, 7-17, https://doi.org/10.1016/j.aeolia.2014.01.002.

Doran, P. T., C. P. McKay, G. D. Clow, G. L. Dana, A. Fountain, T. Nylen, and W. B. Lyons, 2002: Valley floor climate observations from the McMurdo dry valleys, Antarctica, 1986-2000. J. Geophys. Res., 107, 4772, https://doi.org/10.1029/ 2001JD002045.

,-- - A. Fountain, T. Nylen, D. McKnight, C. Jaros, and J. Barrett, 2008: Hydrologic response to extreme warm and cold summers in the McMurdo Dry Valleys, East Antarctica. Antarct. Sci., 20, 499-509, https://doi.org/10.1017/ S0954102008001272.
Elvidge, A. D., and I. A. Renfrew, 2016: The causes of foehn warming in the lee of mountains. Bull. Amer. Meteor. Soc., 97, 455-466, https://doi.org/10.1175/BAMS-D-14-00194.1.

,-- J. C. King, A. Orr, T. A. Lachlan-Cope, M. Weeks, and S. L. Gray, 2015: Foehn jets over the Larsen C Ice Shelf, Antarctica. Quart. J. Roy. Meteor. Soc., 141, 698-713, https:// doi.org/10.1002/qj.2382.

Fountain, A. G., G. L. Dana, K. J. Lewis, B. L. Vaughn, and D. M. McKnight, 1998: Glaciers of the McMurdo Dry Valleys, southern Victoria Land, Antarctica. Ecosystem Dynamics in a Polar Desert: The McMurdo Dry Valleys, Antarctica, J. C. Priscu, Ed., Antarctic Research Series, Vol. 72, Amer. Geophys. Union, 65-76.

- and Coauthors, 1999: Physical controls on the Taylor Valley ecosystem, Antarctica. BioScience, 49, 961, https://doi.org/ $10.2307 / 1313730$.

Hoffman, M. J., A. G. Fountain, and G. E. Liston, 2016: Distributed modeling of ablation (1996-2011) and climate sensitivity on the glaciers of Taylor Valley, Antarctica. J. Glaciol., 62, 215-229, https://doi.org/10.1017/jog.2015.2.

Jepsen, S. M., E. E. Adams, and J. C. Priscu, 2010: Sediment melt-migration dynamics in perennial Antarctic lake ice. Arct. Antarct. Alp. Res., 42, 57-66, https://doi.org/10.1657/ 1938-4246-42.1.57.

Katurji, M., and P. Zawar-Reza, 2016: Forward-looking infrared cameras for micrometeorological applications within vineyards. Sensors, 16, 1518, https://doi.org/10.3390/s16091518.

, B. Noonan, P. Zawar-Reza, T. Schulmann, and A. Sturman, 2015: Characteristics of the springtime alpine valley atmospheric boundary layer using self-organizing maps. J. Appl. Meteor. Climatol., 54, 2077-2085, https://doi.org/10.1175/ JAMC-D-14-0317.1.

Kennedy, A. D., 1993: Water as a limiting factor in the Antarctic terrestrial environment: A biogeographical synthesis. Arct. Alp. Res., 25, 308-315, https://doi.org/10.2307/1551914.

Lin, J. C., C. Gerbig, S. C. Wofsy, A. E. Andrews, B. C. Daube, K. J. Davis, and C. A. Grainger, 2003: A near-field tool for simulating the upstream influence of atmospheric observations: The Stochastic Time-Inverted Lagrangian Transport (STILT) model. J. Geophys. Res., 108, 4493, https://doi.org/10.1029/ 2002JD003161.

Monaghan, A. J., D. H. Bromwich, J. G. Powers, and K. W. Manning, 2005: The climate of the McMurdo, Antarctica, region as represented by one year of forecasts from the Antarctic Mesoscale Prediction System. J. Climate, 18, 1174-1189, https:// doi.org/10.1175/JCLI3336.1.

Nigro, M. A., and J. J. Cassano, 2014: Identification of surface wind patterns over the Ross Ice Shelf, Antarctica, using self-organizing maps. Mon. Wea. Rev., 142, 2361-2378, https://doi.org/10.1175/ MWR-D-13-00382.1.

, — , and M. W. Seefeldt, 2011: A weather-pattern-based approach to evaluate the Antarctic Mesoscale Prediction System (AMPS) Forecasts: Comparison to automatic weather station observations. Wea. Forecasting, 26, 184-198, https:// doi.org/10.1175/2010WAF2222444.1.

, - - and S. L. Knuth, 2012: Evaluation of Antarctic Mesoscale Prediction System (AMPS) cyclone forecasts using infrared satellite imagery. Antarct. Sci., 24, 183-192, https://doi.org/ 10.1017/S0954102011000745.

Nkem, J. N., D. H. Wall, R. A. Virginia, J. E. Barrett, E. J. Broos, D. L. Porazinska, and B. J. Adams, 2006: Wind dispersal of soil invertebrates in the McMurdo Dry Valleys, Antarctica. Polar Biol., 29, 346-352, https://doi.org/10.1007/s00300-005-0061-x. 
Oliphant, A. J., R. C. A. Hindmarsh, N. J. Cullen, and W. Lawson, 2014: Microclimate and mass fluxes of debris-laden ice surfaces in Taylor Valley, Antarctica. Antarct. Sci., 27, 85-100, https://doi.org/10.1017/S0954102014000534.

Outten, S. D., I. A. Renfrew, and G. N. Petersen, 2009: An easterly tip jet off Cape Farewell, Greenland. II: Simulations and dynamics. Quart. J. Roy. Meteor. Soc., 135, 1934-1949, https:// doi.org/10.1002/qj.531.

Pearce, D., P. Bridge, K. Hughes, B. Sattler, R. Psenner, and N. Russell, 2009: Microorganisms in the atmosphere over Antarctica. FEMS Microbiol. Ecol., 69, 143-157, https:// doi.org/10.1111/j.1574-6941.2009.00706.x.

Powers, J. P., K. W. Manning, D. H. Bromwich, J. J. Cassano, and A. M. Cayette, 2012: A decade of Antarctic science support through AMPS. Bull. Amer. Meteor. Soc., 93, 1699-1712, https://doi.org/10.1175/BAMS-D-11-00186.1.

Raphael, M., and Coauthors, 2016: The Amundsen Sea low: Variability, change, and impact on Antarctic climate. Bull. Amer. Meteor. Soc., 97, 111-121, https://doi.org/10.1175/ BAMS-D-14-00018.1.

Richardson, A. J., C. Risien, and F. A. Shillington, 2003: Using self-organizing maps to identify patterns in satellite imagery. Prog. Oceanogr., 59, 223-239, https://doi.org/10.1016/ j.pocean.2003.07.006.

Sammon, J. W., 1969: A nonlinear mapping for data structure analysis. IEEE Trans. Comput., C-18, 401-409, https://doi.org/ 10.1109/T-C.1969.222678.

Seefeldt, M. W., and J. J. Cassano, 2012: A description of the Ross Ice Shelf air stream (RAS) through the use of self-organizing maps (SOMs). J. Geophys. Res., 117, D09112, https://doi.org/ 10.1029/2011JD016857.

, - - and T. R. Paris, 2007: Dominant regimes of the Ross Ice Shelf surface wind field during austral autumn 2005. J. Appl. Meteor. Climatol., 46, 1933-1955, https://doi.org/10.1175/ 2007JAMC1442.1.

Sheridan, S. C., and C. C. Lee, 2011: The self-organizing map in synoptic climatological research. Prog. Phys. Geogr., 35, 109-119, https://doi.org/10.1177/0309133310397582.

Skamarock, W. C., and Coauthors, 2008: A description of the Advanced Research WRF version 3. NCAR Tech. Note NCAR/TN-475+STR, 113 pp., https://doi.org/10.5065/ D68S4MVH.

Smets, W., S. Moretti, S. Denys, and S. Lebeer, 2016: Airborne bacteria in the atmosphere: Presence, purpose, and potential.
Atmos. Environ., 139, 214-221, https://doi.org/10.1016/ j.atmosenv.2016.05.038.

Smith, R. C., and Coauthors, 1999: Marine ecosystem sensitivity to climate change Historical observations and paleoecological records reveal ecological transitions in the Antarctic Peninsula region. BioScience, 49, 393-404, https://doi.org/10.2307/ 1313632.

Speirs, J. C., H. A. McGowan, and D. Neil, 2008: Meteorological controls on sand transport and dune morphology in a polar desert: Victoria Valley, Antarctica. Earth Surf. Processes Landforms, 33, 1875-1891, https://doi.org/10.1002/esp.1739.

_, D. F. Steinhoff, H. A. McGowan, D. H. Bromwich, and A. J. Monaghan, 2010: Foehn winds in the McMurdo Dry Valleys, Antarctica: The origin of extreme warming events. J. Climate, 23, 3577-3598, https://doi.org/10.1175/2010JCLI3382.1.

Sprenger, M., and H. Wernli, 2015: The LAGRANTO Lagrangian analysis tool-Version 2.0. Geosci. Model Dev., 8, 2569-2586, https://doi.org/10.5194/gmd-8-2569-2015.

Stohl, A., and H. Sodemann, 2010: Characteristics of atmospheric transport into the Antarctic troposphere. J. Geophys. Res., 115, D02305, https://doi.org/10.1029/2009JD012536.

_ - M. Hittenberger, and G. Wotawa, 1998: Validation of the Lagrangian particle dispersion model FLEXPART against large scale tracer experiments. Atmos. Environ., 32, 4245-4264, https://doi.org/10.1016/S1352-2310(98)00184-8.

Tastula, E. M., T. Vihma, and E. L Andreas, 2012: Evaluation of Polar WRF from modeling the atmospheric boundary layer over Antarctic sea ice in autumn and winter. Mon. Wea. Rev., 140, 3919-3935, https://doi.org/10.1175/MWR-D-12-00016.1.

Taylor, P. D., L. Fahrig, K. Henein, and G. Merriam, 1993: Connectivity is a vital element of landscape structure. Oikos, 68 , 571-572, https://doi.org/10.2307/3544927.

Wernli, B. H., and H. C. Davies, 1997: A Lagrangian-based analysis of extratropical cyclones. I: The method and some applications. Quart. J. Roy. Meteor. Soc., 123, 467-489, https://doi.org/ 10.1002/qj.49712353811.

Wille, J. D., D. H. Bromwich, M. A. Nigro, J. J. Cassano, M. Mateling, M. A. Lazzara, and S. H. Wang, 2016: Evaluation of the AMPS boundary layer simulations on the Ross Ice Shelf with tower observations. J. Appl. Meteor. Climatol., 55, 23492367, https://doi.org/10.1175/JAMC-D-16-0032.1.

Zawar-Reza, P., and M. Katurji, 2014: Antarctic climate and soils. Antarctic Terrestrial Microbiology, Cowan D., Ed., Springer, 279-292. 